\title{
Expedições de conquista ibérica e tentativas de submeter os povos indígenas do Pantanal ao domínio europeu no século XVI
}

\author{
Iberic expedictions of conquer and tentatives of subbmit \\ the Pantanal indigenous people to the european dominium \\ on the XVI century
}

João Filipe Domingues Brasil ${ }^{1}$

DOI: http://dx.doi.org/10.20435/tellus.v19i39.528

Resumo: O presente artigo tem como proposta central abordar as expedições de conquista ibérica e tentativas de submeter os povos indígenas do Pantanal ao domínio europeu no século XVI. O objetivo do trabalho é contribuir para a melhor compreensão da história dos povos indígenas da região em um contexto mais amplo, ligado à história da região platina frente às ações dos invasores europeus. Para este propósito, foi realizado um levantamento bibliográfico e documental sobre o tema, contido, sobretudo, em fontes primárias, sendo elas os relatos feitos pelos expedicionários Ulrico Schmidl e Álvar Núñez Cabeza de Vaca, e secundárias, à luz da etno-história.

Palavras-chave: conquista ibérica; etno-história; história indígena; povos indígenas do Pantanal.

Abstract: This article's main purpose to approach the expeditions of Iberian conquest and attempts to submit the indigenous peoples of the Pantanal to the European domain in the 16th century. The aim of this article is to contribute to the apprehension the indigenous people's history of the region in wide context, linked to the platinum region's history in the face of the actions of European invaders. For this purpose, a bibliographic research was realized on this subject, mainly focused on primary sources, being them the reports made by Ulrico Schmidl and Álvar Núñes Cabeza de Vaca, and secundary sources, under the prism of ethnohistory.

Keywords: ethnohistory; iberian conquest; indigenous history; native-born from Pantanal

1 Universidade Salgado de Oliveira (UNIVERSO), São Gonçalo, Rio de Janeiro, Brasil. 


\section{CONSIDERAÇÕES INICIAIS}

No período colonial, a região atualmente denominada de Pantanal era mencionada na cartografia europeia como Laguna de los Xarayes. Trata-se de um bioma conhecido por abranger uma grande planície de inundação, a maior área alagável contínua do globo, localizada na bacia hidrográfica do alto curso do rio Paraguai. Possui uma extensão de aproximadamente 250 mil km², distribuída em parte dos atuais territórios nacionais do Brasil, Bolívia e Paraguai.

Ao longo do século XVI, a região foi atingida por várias expedições ibéricas, sobretudo espanholas, as quais inicialmente tinham o propósito de conquistar territórios ricos em metais preciosos ${ }^{2}$. Para isso, buscavam submeter ao domínio europeu os povos indígenas ali estabelecidos desde tempos pré-coloniais (EREMITES DE OLIVEIRA, 2003).

No presente estudo, tais expedições serão abordadas à luz da etno-história, buscando revelar o protagonismo indígena presente em tais processos. Acerca da utilização proposta para a etno-história no presente artigo, partilho da compreensão de Jorge Eremites de Oliveira, entendendo que a

Etno-história não deve ser reduzida à noção de uma história anacrônica, exótica, emic e essencialista dos povos indígenas, tampouco percebida como uma proposta restrita aos povos indígenas outrora estudados quase que exclusivamente por etnólogos. Deve ser compreendida para muito mais além, inclusive como uma perspectiva metodológica interdisciplinar - ou disciplina híbrida como alguns defendem- que tem por objetivo estudar a história e a cultura de povos e comunidades tradicionais, como indígenas, quilombolas, ribeirinhos, etc. (EREMITES DE OLIVEIRA, 2012, p. 191).

Para se alcançar o objetivo aqui proposto, será realizada primeiramente uma caracterização da região do Pantanal no século XVI, através, sobretudo, de fontes bibliográficas secundárias, para em seguida, serem abordados os principais relatos acerca das expedições que cruzaram o Pantanal no século XVI, as fontes primárias do estudo.

2 O termo "conquista", embora recorrente na historiografia, precisa ser relativizado porque os povos indígenas contemporâneos não se sentem conquistados pelos europeus ou pelos euroamericanos, pelo contrário. Percebem-se como protagonistas de uma longa história marcada por várias estratégias de resistência a todo tipo de situação de dominação e exploração a eles impostas pelos invasores de além-mar e seus sucessores. 
Ao se realizar tal caracterização, é possível compreender melhor a descrição dos relatos que se segue, tomando por referência os Povos Indígenas nele presentes. Pelo espaço disponível para a realização do trabalho, aborda-se as fontes primárias de maneira mais descritiva que analítica. Contudo, com a utilização da etno-história enquanto método de pesquisa, tal abordagem permite vislumbrar o protagonismo indígena frente aos processos de conquista e colonização espanhola na região do Pantanal a partir do século XVI. Sigamos agora para a caracterização espacial e temporal do tema estudado.

\section{EXPEDIÇÕES E DINÂMICAS COLONIAIS NO PANTANAL DO SÉCULO XVI}

Denominado pelo português Juan Diaz de Solís como Mar Dulce, por isso também conhecido no começo do século XVI como rio de Solís, a confluência entre os rios Paraná e Paraguai receberá o nome de rio da Prata após o retorno com ouro e prata de parte da expedição do também português Aleixo Garcia, morto provavelmente por índios Payaguá no caminho de volta da primeira expedição que alcançou o Pantanal ou Alto Paraguai.

A partir da década de 1530, toda uma rede de administração foi montada para exploração e colonização das novas terras a partir do rio da Prata. Neste contexto, observa-se que as tentativas de conquista da bacia do Alto Paraguai estão ligadas ao processo de conquista ibérica da bacia platina, bem como a uma rede administrativa vinculada às coroas Portuguesa e Espanhola.

A grande quantidade de metais preciosos que Francisco Pizarro e seus homens encontravam no Peru fez com que Carlos V, à época rei da Espanha, entregasse a responsabilidade sobre a província do Rio da Prata a Pedro de Mendoza. Na condição de primeiro adelantado da região, ele recebeu patrocínio privado e montou sua expedição, que contava, entre outros nomes, com "o alferes geral da infantaria Alonso Cabrera, e os capitães Felipe de Cáceres e Domingo Martinez de Irala" (MARKUN, 2009, p. 134), além do lansquenete alemão Ulrico Schmidl.

Chegando ao rio da Prata em 1536, Mendoza e seus homens fundam o forte de Nossa Senhora de Buenos Aires, vivendo entre relações amistosas e conflituosas com os Charrua e Carendí ou Querandí, assim chamados genericamente, que primeiramente lhes forneceram mantimentos, como forma de estabelecer relações de aliança e reciprocidade. Posteriormente, diante das ações dos conquistadores, 
impuseram-se belicamente aos invasores espanhóis. Sentindo as dificuldades de se adaptar àquele ambiente e diante da dificuldade das relações com os povos indígenas estabelecidos na região, o adelantado despachou "seu braço direito, o alguazil Juan de Ayolas, à procura de uma região fértil e supostamente rica descrita por Caboto em seu mapa-múndi" (MARKUN, 2009, p. 136).

A expedição realizada sob o comando de Juan de Ayolas, no ano de 1537, foi a primeira a alcançar o Alto Paraguai: "remontó el río Paraguay hasta un lugar que llamó La Candelaria, porque llegó ahí el 2 de febrero" (COMBÈS, 2010, p. 8). O local fundado por Ayolas e seus subordinados ficou conhecido como Porto da Candelária e se tornou importante local para a circulação fluvial dos espanhóis no Pantanal colonial. Sua localização é muito discutida e controversa, gerando diferentes interpretações (COMBÈS, 2010).

Depois de fundar o Porto da Candelária, Ayolas fez uma entrada à região, deixando em seu posto o capitão Domingo Martinez de Irala. Pedro de Mendoza, que não recebia notícias de seu braço direito há muito tempo, "enviou o jovem capitão Juan Salazar de Espinosa em busca de Ayolas. Durante a viagem, Espinosa fundou o forte de Nossa Senhora de Santa María de la Asunción, futura capital da província" (MARKUN, 2009, p. 138). Assunção, como será nomeada mais tarde, desempenhará papel estratégico nas futuras expedições em busca de metais preciosos e tentativas de conquista dos índios nas regiões do Chaco e do Pantanal, dentre outras, como a Província do Guairá (EREMITES DE OLIEIRA; ESSELIN, 2015, p. 281).

Enquanto Assunção era fundada no médio curso do rio Paraguai por Espinosa e seus comandados, Buenos Aires passava por inúmeras dificuldades, as quais resultaram no retorno de Pedro de Mendoza à Espanha. O primeiro adelantado do Rio da Prata, contudo, não chegou ao seu destino final, pois pereceu em alto mar durante o caminho de volta. Com isso, os investidores de Mendoza conseguiram que a coroa espanhola enviasse dois navios de auxílio para Buenos Aires. Sobre o assunto, cumpre destacar o seguinte:

Em mais um indício da esperança geral de que o Rio da Prata faria jus ao nome, num deles seguia Alonso Cabrera, agora com o posto de inspetor de minas. Além da autoridade para controlar a exploração de qualquer jazida, Cabrera levava ordens de confirmar no posto o homem que Mendoza tivesse deixado no comando da província. Em caso de dúvida, ou da vacância 
Expedições de conquista ibérica e tentativas de submeter os povos indígenas do Pantanal ao domínio europeu no século XVI

do poder, conquistadores e colonos poderiam eleger um novo dirigente. (MARKUN, 2009, p. 138).

A chegada de Cabrera a Buenos Aires, em 1538, causou uma disputa pelo poder da Província do Rio da Prata. Ocorre que Mendoza havia deixado Francisco Ruiz Galán no comando local e Espinosa continuava a procurar Ayolas, sucessor imediato de Mendoza. Irala, que aguardou Ayolas no Porto da Candelária por meses, sem notícias do oficial, desceu a Assunção. Galán resolvera subir de Buenos Aires até aquela localidade e, depois de chegar ao forte, tomou a seguinte providência:

[...] prendeu Irala, sob acusação de abandono do posto. Mas logo recuou, diante dos argumentos do capitão e da pressão de outros oficiais. Como Ayolas não regressou, os colonos resolveram ir às urnas, digamos. Irala nem precisou disputar: foi aclamado governador. (MARKUN, 2009, p. 139).

Por este motivo, Domingo Martinez de Irala é oficialmente considerado o primeiro governador de Assunção. Depois de procurar mais uma vez por Ayolas e a Serra de Prata, sem sucesso, Irala "decidiu concentrar em Assunção todos os espanhóis, mandando despovoar Buenos Aires" (MARKUN, 2009, p. 139). A imposição de sua decisão, contrariando a vontade de muitos colonos, pode dar alguma ideia sobre o modo de Irala governar, o que deve ter colaborado para ele ser denominado algumas vezes como autoritário e ter tido uma conhecida desavença com o segundo adelantado do Rio da Prata, Álvar Nuñez Cabeza de Vaca.

Sobre Assunção, assim explica Markun (2009, p. 139):

Nova capital do Rio da Prata, Irala distribuiu terras e casas, construiu uma paliçada, organizou um gabinete e nomeou autoridades - atos que ajudaram a transformar o forte precário numa cidade de verdade, cujo nascimento foi juridicamente formalizado em 16 de setembro de 1541.

Irala ainda fez duas expedições pelo Alto Paraguai, a primeira entre 1542 e 1543, e a segunda entre 1547 e 1548, sendo que esta última pode ser considerada como "el primer viaje trans-Chaco exitoso de los españoles de Asunción" (COMBÈS, 2010, p. 9). Além dessas e das expedições apontadas anteriormente, em 1556, após a morte do adelantado, Ñuflo de Chávez comandou outra expedição à região.

Ñuflo de Chaves hizo una última expedición de exploración desde Asunción, subiendo el río Paraguay hasta llegar en 1557-58 otra vez al Pantanal, esta 
vez en busca de "el Dorado". No se sabe por qué decidió dirigir su compañía hacia el oeste del Pantanal en vez de al norte, donde habían tenido noticias de grupos con muchos objetos de oro, pero así lo hizo. Otra vez, la exploración les llevó a la región de la actual Santa Cruz, pero por una ruta que salía del Pantanal, posiblemente la ruta de García. A orillas del río Guapay, en agosto de 1559, Ñuflo de Chaves fundó un pueblo llamado "la nueva Asunción", también conocido como "La Barranca". Cuando estuvo en esta región con Irala en 1548, vivían allí grupos sujetos a una encomienda charqueña, pero la situación había cambiado. Para abrir el camino hacia Charcas, Chaves mandó llamar a Vitupué, el jefe de un grupo de chiriguanáes que tenía su pueblo en el lugar donde el río Grande (o Guapay, o Chungará) sale de la cordillera y entra en los llanos. (JULIEN, 2008, p. 8).

Chávez veio para a América do Sul na expedição de Cabeza de Vaca. Acompanhou o adelantado em suas entradas e ficou na província do Prata quando o governador foi preso e enviado de volta à Espanha, passando, a partir de então, a servir a Irala. Julien (2008, p. 4-86) explica que há a publicação de um documento intitulado Relación de los casos en que el capitán Nufrio de Chaues ha servido a Su Majestad desde el año de 1540. Santa Cruz de la Sierra, 1.VI.1561, no qual o próprio Chávez discorre sobre seus serviços prestados à Coroa Espanhola. Além do caráter de prestação de contas, no documento aparece uma forma do oficial pleitear encomiendas na cidade que fundara em 1561, Santa Cruz de la Sierra, pertencente à jurisdição de Charcas.

Caracterizado o estudo em relação aos recortes espacial e temporal proposto, seguiremos aos relatos de Ulrico Schmidl e Álvar Núñez Cabeza de Vaca, vislumbrando o protagonismo indígena frente aos processos que descrevem.

\section{OS RELATOS DE ULRICO SCHMIDL}

Ulrico Schmidl ${ }^{3}$ partiu de Amberes, Espanha, em 1534, na expedição de Pedro Mendoza, primeiro adelantado do Rio da Prata. Chegou ao Rio de Janeiro no mesmo ano, relatando a existência de índios Tupi na região. Em todo seu relato, Schmidl utiliza o termo Guarani apenas uma vez (SCHMIDL, 1986, p. 154). No entanto, não acentua a existência de diferenças étnicas, culturais e geracionais entre os povos indígenas falantes do idioma guarani. Denomina apenas os Cario,

3 Para maiores informações sobre o nome Ulrico Schmidl, ver Mitre (1903, p. 13-20). 
seus acompanhantes durante todo o percurso, desde o atual litoral brasileiro até o Alto Paraguai. Tal fato pode ser explicado considerando que "su nombre se volvió rápidamente sinónimo de "guaraní-hablante", al igual que poco después el término "chiriguanaes" (COMBÈS, 2010, p. 86).

Navegando do litoral brasileiro até a primeira Buenos Aires, seguindo o Rio Paraná acima, após atingirem o rio Paraguai, Schmidl relata o encontro com os Kueremagbei, do qual também quase nada se sabe em termos historiográficos. Navegando rio acima encontram os Agace, povo linguisticamente filiado à família linguística Guaikuru, pertencentes ao povo Payaguá, dos quais o relato de Schmidl vai ao encontro. Depois dos Agace, chegaram aos Cario, dos quais Schmidl faz um denso relato, atestando a existência de antropofagia entre eles (SCHMIDL, 1986, p. 171-2). Além disso, indica que possuíam nucleações ao longo do rio, como a de Lambaré, nome que faz referência à presença de um cacique assim denominado, a qual os espanhóis conseguiram destruir, mas não sem resistência por parte dos indígenas (SCHMIDL, 1986, p. 173-6).

Após a conquista de Lambaré, os espanhóis fundaram a cidade de Nossa Senhora de Assunção, a primeira Assunção, em 1537 (SCHMIDL, 1903). Celebraram um contrato com os Cario, com quem construíram relações de aliança política. A partir de então, os Cario teriam passado a servir os espanhóis e acompanhá-los em suas guerras, a primeira realizada contra os Agaces (SCHMIDL, 1986, p. 177), seus inimigos também. Nessa guerra, os espanhóis realizam uma entrada na qual encontram os Xaray, Caracará, Payaguá, Payzuno, Naperu e Mbayá-Guaikuru.

O relato de Schmidl corrobora com o de Cabeza de Vaca, situando essas populações entre Assunção e Porto de los Reyes. Nessa primeira entrada os espanhóis fundam o importante Porto da Candelária. Apesar da causa principal apontada por Schmidl para a entrada ser a guerra contra os Agace, e posteriormente contra os Payaguá e Guaikuru, podemos observar que a procura por metais preciosos norteia todo sentido da expedição, que não conseguiu chegar aos atuais territórios andinos da Bolívia e do Peru.

Após a volta dos espanhóis para Assunção, Schmidl aponta que Irala foi escolhido para substituir Ayolas no comando espanhol, conforme visto anteriormente, durante uma rusga ocorrida entre Irala e Francisco Ruiz Galán. Sob o comando de Irala, os espanhóis retornaram a Buenos Aires em 1541, fundando 
o porto de Corpus Christi, destruído posteriormente durante a guerra contra os Timbu, deixando muitos mortos de ambos os lados.

Schmidl retornou com Irala à Assunção, ocasião em que tomaram conhecimento da vinda de Cabeza de Vaca como adelantado. Acompanhando-o em suas entradas pelo Pantanal, ratifica em seu texto a existência dos "Orejones". Também cita os Yacaré, provavelmente os Artanese mencionados no relato de Cabeza de Vaca (COMBÈS, 2010, p. 331). Schmidl indica que acompanhando Hernando de Ribera, ordenado por Cabeza de Vaca, procurou alcançar por terra adentro, provavelmente a noroeste de Porto de los Reyes, a região amazonense, terra das lendárias amazonas ${ }^{4}$, guiados por informações recebidas dos Siberi e Urtuese (Ortuese), possivelmente populações Xaray (COMBÈS, 2010, p. 287).

Após essa entrada, e as muitas mazelas provocadas por ela, realizada em época de cheia na planície pantaneira, Schmidl tomou partido de Irala na sublevação contra Cabeza de Vaca. Após o então adelantado ser enviado de volta à Espanha como prisioneiro, Schmidl narra que houve muita instabilidade entre os espanhóis, e que entraram em guerra contra os Agace, com a ajuda dos Cario e dos Guatata, que seriam uma geração dos Guaikuru. A descrição das batalhas revela parte da cultura material das etnias envolvidas. Nessa parte do relato aparece pela primeira vez a menção de um escalpo realizado por um indígena Guaikuru.

Após um longo período de batalhas, os espanhóis conseguiram submeter algumas populações ao domínio europeu, ao que tudo indica de diferentes caciques, como Tabaré, Karaíba, Yeruquihaba e Xexuy. Algumas dessas populações provavelmente seriam falantes do guarani. Ademais, os Cario se transformaram em inimigos dos espanhóis em meio à batalha, revelando que os indígenas poderiam utilizar a aliança com os espanhóis a seu favor em antigas guerras interétnicas, surpreendendo eventuais povos inimigos.

Schmidl assinala que essa guerra durou até 1546. Em 1548, Irala resolve realizar nova entrada pelo Pantanal, tentando alcançar a região andina, novamente em sentido noroeste. Entram desde o Porto de los Reyes pelos já mencionados

\footnotetext{
4 Os espanhóis, através de notícias que corriam entre os indígenas, assim como as sobre a Serra de Prata, imaginavam existir acima do Alto Paraguai uma sociedade indígena com mulheres que montavam a cavalo e detinham inúmeras provisões e riquezas. Daí o motivo da entrada ordenada por Cabeza de Vaca.
} 
Naperú, passando pelos Payaguá e Guaikuru, agora nomeados Mbayá. Schmidl revela que os Mbayá, na época dessa entrada, não possuíam cavalos. Sendo assim, há possibilidade de que os cavalos tenham sido gradualmente incorporados à antigos Mbayá a partir desse contato. Os Mbayá também foram nomeados por Schmidl como Mayaeide e Maiaie, sendo os primeiros provavelmente os Kadiwéu que também ocupavam parte da Serra da Bodoquena.

Em sentido noroeste, Schmidl narra, respectivamente, o encontro com as seguintes povos indígenas: Chané, Chamacoco e Chiquito, apelativos que poderiam ser empregados pelos indígenas falantes do guarani a diferentes populações (COMBÈS, 2010); Payhono (Payono), localizados "entre os Toyana e Mayágono" (COMBÈS, 2010, p. 235); Toyana (Thohana), prováveis "vassalos" dos Mbayá; Moriono (Morrono), possíveis Moro (COMBÈS, 2010, p. 208); Perrono e Sunenno (Zatieno), dos quais quase não se tem referência, podendo ser gerações Chané; Guorcono (Borkene), que se localizavam entre os Simeno e os Layono (COMBÈS, 2010, p. 169); Carcono, vizinhos dos Guorcono; Mayágono (Maygenno), os quais mantiveram boas relações com os espanhóis, abastecendo-os de alimentos (COMBÈS, 2010, p. 198); Gorgotoqui, geração de indígenas que viviam no local de fundação da primeira Santa Cruz la Vieja, por Ñuflo de Chávez; e por último, os Macasi, que vivam às margens do rio Guapay ou Grande.

Durante todo o caminho, Schmidl descreve o intenso ambiente, os animais, peixes e mantimentos existentes entre os indígenas, além dos costumes deles, que saltam muito aos olhos do alemão. Após essa entrada, feita de comunidade a comunidade, os espanhóis chegaram à região andina, ainda em 1548, e reconheceram que lá estava a terra de riquezas que tanto procuravam, conforme ele mesmo descreve:

Esta tierra del Perú era a todas luces delante de Dios y del mundo, de él Consulo Piesiro, en razón de que él junto con sus hermanos Margose (el Marqués) y Ernando Piesieron (Hernando Pizarro), habían sido los primeros de todos que descubrieron y conquistaron la tierra del tal reino. Esta tierra con razón se llama tierra rica; porque todas las riquezas que posee la Cesárea Majestad salen del Perú y de Nove Hispaniam (Nueva España) y Terra firma (Tierra Firme). (SCHMIDL, 1903, p. 267).

Irala, governador de outra jurisdição ou província, não poderia entrar com seu exército onde já havia encomiendas de espanhóis: 
Mandó a cuatro españoles a comunicarse con las diferentes autoridades, dos a Charcas y dos a Lima. Ñuflo de Chaves fue uno de los españoles enviados a Lima. Estos cuatro españoles fueron los primeros - que sepamos - en cruzar la frontera de lo que había sido el imperio incaico desde el oriente. (JULIEN, 2008, p. 7).

Segundo o relato de Schmidl, ele teria sido um dos quatro escolhidos por Irala para ir até a região andina do Peru, e lá teria recebido uma carta de seu irmão, solicitando seu retorno à Europa, o que fez em seguida, retornando pelo Pantanal até o porto de São Vicente, na atual região de Santos, estado brasileiro de São Paulo.

O relato de Schmidl permite realizar algum mapeamento étnico do rio Paraná, abaixo da influência com o Paraguai, e do caminho de Porto de los Reyes, até a primeira Santa Cruz, la Vieja, além de corroborar com os dados do relato de Cabeza de Vaca. Por isso, torna-se importante para o entendimento da história dos povos indígenas no Pantanal do século XVI.

\section{OS RELATOS DE ÁLVAR NÚÑEZ CABEZA DE VACA}

O espanhol Alvar Nuñez Cabeza de Vaca, autor das obras Naufrágios e Comentários,

[...] es uno más de la larga lista de cronistas que por una u otra razón participaron en la enorme gesta ibérica de la evangelización, conquista y colonización de las Américas, el Pacífico, Asia y África, buena parte del Mediterráneo y Europa en el siglo XVI. (MAURA, 2011, p. 11).

O fato de Cabeza de Vaca ter sido enviado à América do Sul como adelantado do Rio da Prata, motivo de conflitos com Irala, quem pensava em ocupar o cargo, demonstra que há algum tempo a coroa espanhola não recebia notícias daquela província. Devemos considerar a particularidade da expedição de Cabeza de Vaca e da política colonialista empregada por ele. Isso certamente não destoa esta das outras expedições realizadas à época das grandes navegações europeias, geralmente realizadas em servidão à Coroa Espanhola ou Portuguesa, em nome de Deus e da Igreja e em busca de ouro e prata.

Desembarcando em Santa Catarina, Cabeza de Vaca assinala que navegou, entre outros rios, pelo Iguaçu e pelo Paraná, sempre acompanhado de indígenas 
falantes da língua guarani, de diversas gerações e diferentes etnias, contatando diversos caciques, os quais os abasteciam e efetuavam as sabidas trocas, refazendo assim em parte o caminho do Peabiru, até chegar em Assunção.

O ambiente marcante mereceu atenção especial de Cabeza de Vaca durante seu caminho, pois destacava alguns barcos e pessoas de sua expedição para procurarem outras rotas e contatarem com diferentes comunidades indígenas. Destacou também que essa se tratava da "la mas fertil tierra del mundo muy aparejada para labrar y criar" (CABEZA DE VACA, 1555, p. 137).

Cabeza de Vaca permaneceu de 1542 a 1543 em Assunção, realizando expedições rio Paraguai acima e terra adentro, até ser preso e mandado como prisioneiro para a Europa. Chegando em Assunção em 11 de março de 1542, tomou seu posto de adelantado perante todos os espanhóis. Em pouco tempo mandou socorro aos espanhóis que ainda permaneciam em Buenos Aires e que "a los índios que habitavan en el rio del Parana, por donde avian de navegar, les hiziessen buenos tratamientos, y los truxessen de paz a la obediencia de su magestad" (CABEZA DE VACA, 1555, p. 147). Essa passagem é um dos exemplos da política que Cabeza de Vaca tentou implementar sem sucesso durante as tentativas de conquista ibérica da região do Pantanal.

No capítulo XVI dos Comentários (CABEZA DE VACA, 1555, p. 149-50), o adelantado descreve o ritual antropofágico dos índios falantes do guarani que residiam próximos a Assunção, possivelmente os Cario. No capítulo que se segue, localiza os Agace, "a la ribera deste rio del Paraguay", sendo essa "una gente muy temida de todas las nasciones de aquella tierra" (CABEZA DE VACA, 1555, p. 151).

Cabeza de Vaca constantemente narra os conflitos existentes entre os Guarani e os Guaikuru. Devemos considerar que os primeiros souberam utilizar o fator de se aliarem aos espanhóis para alterarem a dinâmica de relações interétnicas com os Guaikuru, que em vários momentos estiveram em guerra contra os Guarani que ali viviam. Além disso, os Agace ou Guaikuru amiúde estabeleciam e rompiam alianças com espanhóis, também aproveitando a presença dos europeus para alterarem a dinâmica de relações interétnicas na região.

Após alguns meses em Assunção, administrando a instável relação entre indígenas e espanhóis, com revoltas e uma alteração na política indigenista por ele adotada, Cabeza de Vaca organizou em julho de 1542 uma expedição rio Paraguai 
acima, contando mais uma vez com a ajuda de indígenas falantes do guarani. Eles o auxiliam no caminho, foram guias, carregadores de materiais e equipamentos diversos (inclusive os barcos, se necessário) e também tradutores.

Com a presença ameaçadora dos Guaikuru, caminhavam de comunidade a comunidade buscando convertê-los e torná-los "amigos da coroa", mas, acima de tudo, buscava encontrar a Serra da Prata e o tesouro roubado de Juan de Ayolas, quando da sua morte, o que nem sempre fica claro nos Comentários.

Os primeiros indígenas relatados nessa expedição foram os Merchires e Guatata, ao que tudo indica populações falantes das línguas guarani e guaicuru, respectivamente, estabelecidas ao longo do rio Paraguai. Provavelmente, esta primeira expedição de Cabeza de Vaca foi motivada pela tentativa de "conquistar" os Guaikuru, pois a perseguição a eles está presente em várias partes de seus relatos.

Outra população encontrada no rio Paraguai foi a dos Yapirúe ou Naperú, assim como a dos Aperú. Possivelmente são uma mesma população de falantes da língua guaikuru (COMBÈS, 2010, p. 167).

Essa primeira entrada de Cabeza de Vaca durou cerca de quatro ou cinco meses, voltando os espanhóis para Assunção após a expedição. A ajuda aos espanhóis e o repovoamento de Buenos Aires passaram a ser a preocupação maior de seu governo, haja vista que Assunção estava fortalecida no começo de 1543. No entanto, "na madrugada de 4 de fevereiro daquele ano, uma cabana de palha situada no meio do povoado pegou fogo. Em minutos, o vento espalhou a chama para todos os lados" provocando um incêndio que, segundo relatos da época, "durou quatro dias e quatro noites, e destruiu 80\% das casas" (MARKUN, 2009, p. 176).

Logo em seguida, ainda em fevereiro de 1543, Irala voltou de uma entrada que havia feito pelo rio Paraguai acima, chegando à região do Pantanal, com a notícia que houvera localizado próximo ao local denominado Porto de los Reyes os Çacoci-Chané, possivelmente uma das várias comunidades que compunham os chamados Orejones (COMBÈS, 2010, p. 220). Irala ainda informou a existência de ouro e prata entre os indígenas e que os mesmos poderiam ensinar o caminho para outras comunidades que também possuíam metais preciosos (CABEZA DE VACA, 1555, p. 189-90). Após consulta realizada junto a seus capitães e clérigos, resolveu realizar uma nova entrada em busca dessas "notícias" trazidas por Irala. 
Dessa forma, reunindo grande número de espanhóis e indígenas falantes do guarani, Cabeza de Vaca seguiu a orientação dos Chané (Çacoci) e partiu com sua expedição do Puerto de los Reyes, acima de Assunção, rumo à porção setentrional do rio Paraguai e terra adentro a oeste, ou seja, pela região do Pantanal.

Segundo o relato, a expedição seguiu rio Paraguai acima pelos portos de Giguy, Guaviaño, Tapua, Itaqui, Guacani e Ipananie até chegarem aos Payaguá, povo canoeiro filiado linguisticamente à família Guaikuru. Todos esses portos, ao que parece, referiam-se a nomes de caciques indígenas que se estabeleciam ao longo do médio e do alto curso do rio Paraguai, a fim de prestar auxílio aos espanhóis.

Atingiram em outubro de 1543 o Porto da Candelária, importante local de circulação espanhola durante a "conquista" ibérica do Pantanal, afirmando que se tratava de "la tierra de los indios Payaguaes" (CABEZA DE VACA, 1555, p. 202). Ali, souberam do tesouro "roubado" de Juan de Ayolas, quando este teria morrido, e decidiram tentar recuperá-lo dos Chané, assim o fazendo com a ajuda dos Payaguá. Adentraram-se, então, por terra até chegarem aos Matara, possivelmente mais um povo dos "Orejones". Continuando a caminhada e navegação por rios menores, afluentes do rio Paraguai, chegaram posteriormente aos Guaxarapo (Guasarapo), os quais teriam se aliado com os "Orejones" contra os espanhóis (COMBÈS, 2010, p. 166). Ainda alcançaram na mesma região os Sococi e Xaquete, também povos "Orejones", estabelecendo ralações traiçoeiras com ambos.

No capítulo LII dos Comentários, Cabeza de Vaca (1555, p. 213-5) realiza uma descrição dos hábitos dos Guaxarapo, assinalando a existência de ouro entre eles. Cabeza de Vaca e seus comandados seguiram, não sem percalços, adentrando o Alto Paraguai e contatando os povos indígenas que encontraram pelo caminho. Caminharam um grande trecho junto aos "Orejones" até chegarem aos Maya, população linguisticamente guaikuru que recebeu esse apelido guarani, assim como os Mbayá, e que no século XVI "vivían más al norte de Asunción, y más "Chaco Adentro" (COMBÈs, 2010, p. 195).

Os Maya, segundo o relato, mantinham guerra contra os Chimeneo, que possuíam muitos metais e são "asociados con los payzunos en las funtes, y bien pudieron constituir una "parcialidad" de estos útimos" (COMBÈS, 2010, p. 127); e também contra os Carcara (Caracará), também possuidores de metais. Os mesmos 
Maya indicaram a existência de outros grandes povos que habitavam perto deles, "que se llaman Gorgotoquies, Payçuñoes, Estarapecocies, y Candires" (CABEZA DE VACA, 1555, p. 223). Esses povos seriam os Gogotoqui, Payzuno, Estarapecoci e Candiré, e localizavam-se no caminho entre o Puerto de los Reyes e a antiga cidade de Santa Cruz la Vieja, entre as zonas I e IV do mapeamento realizado por Combès (COMBÈS, 2010, p. 57), que se refere à rota para se chegar à Sierra de la Prata, tão procurada pelos espanhóis.

Há também no relato de Cabeza de Vaca a menção aos Xaray. O fato de o Pantanal ter sido conhecido durante muito tempo na cartografia como a Lagoa dos Xarayes reforça a ideia do quanto os espanhóis ficaram impressionados com esse povo. Após estarem com os Xaray, os espanhóis chegaram aos Artanes.

Entre os Artanes, Cabeza de Vaca manteve contato com um guia falante do guarani provindo do Itatim, que havia sido tomado como prisioneiro. Os indígenas do Itatim, que também eram falantes do idioma guarani, ao que tudo indica, passaram a acompanhar as expedições espanholas depois desse contato. Torna-se difícil saber, contudo, se tal fato ocorreu antes ou depois do evento narrado por Cabeza de Vaca.

No caminho de volta da expedição, próximo ao Porto de los Reys, Cabeza de Vaca identifica os Arrianicosi, índios agricultores que se negaram a ajudá-los (COMBÈS, 2010, p. 67). Essa passagem torna representativa pela forma como as cheias anuais do Pantanal afetaram diretamente os espanhóis. Eles já não tinham como se abastecerem e ainda viram os indígenas Ihes negarem apoio, como os Guaxarapo e Guató, povos que se uniram em guerra contra os invasores espanhóis. Segue uma passagem dos Comentários que trata do assunto:

Tres meses estuvo el gobernador en el Puerto de los Reyes con toda la gente enferma de calenturas, y él con ellos, esperando que Dios fuese servido de darles salud y que las aguas bajasen para poner en efecto la entrada y descubrimiento de la tierra, y de cada día crecía la enfermedad, y lo mismo hacían las aguas. (CABEZA DE VACA, 1922, p. 328).

A segunda entrada de Cabeza de Vaca no Alto Paraguai durou cerca de nove meses. Quando voltou para Assunção, com muitas baixas e enfermos, foi preso junto com seus capitães sob denúncias de "traidor, autoritário e incompetente" (MARKUN, 2009, p. 177-8), e mandado de volta à Espanha em 1544. 
O relato produzido por ele é fundamental para entender o contexto étnico do Alto Paraguai, Assunção, até o Puerto de la Candelária, Puerto de los Reyes, e ao oeste, rumo em direção à antiga Santa Cruz la Vieja.

\section{CONCLUSÃO}

A partir da década de 1520, expedições ibéricas começaram a percorrer a região atualmente conhecida como Pantanal em busca da lendária Sierra de la Prata e da conquista de territórios e submissão dos povos indígenas ao domínio espanhol. A primeira expedição que atingiu o Alto Paraguai é a de Aleixo Garcia, sobrevivente do naufrágio da expedição de Juan Díaz de Solís na região que viria a ser a província do Rio da Prata, batizada por ele de Mar Dulce. O português teria sido morto por indígenas no trajeto de volta. A coroa espanhola, desejando a grande riqueza que pensava existir na região, destinou a expedição de Pedro de Mendoza para explorá-la. O primeiro adelantado do Rio da Prata, por sua vez, ordenou que Juan de Ayolas percorresse o norte da região em busca de riquezas, sobretudo metais preciosos.

Ao alcançar o Alto Paraguai, Ayolas realizou entrada da qual não volta, deixando Domingo Martinez de Irala em seu lugar, acompanhado de Ulrico Schmidl, que ao retornar à Alemanha publicou importante relato sobre o assunto. Após anos sem informação da província do Rio da Prata, a coroa espanhola enviou à região a expedição do então adelantado Álvar Nuñez Cabeza de Vaca. Apesar das melhorias que Irala aparentemente realizou na província do Rio da Prata, suas firmes posições desagradaram muitos colonos, como no episódio da transferência da capital da província de Buenos Aires para Assunção, e culminou em uma rusga entre ele e Cabeza de Vaca.

Cabeza de Vaca realizou duas entradas na região do alto curso do rio Paraguai, onde está situado o Pantanal, antes de ser preso e mandado de volta para a Espanha e depois publicou seus Comentários, outro importante relato da época. Ñuflo de Chávez ainda realizou uma entrada no Alto Paraguai, dali partindo para fundar Santa Cruz de la Sierra, em 1561.

Os relatos das expedições abordados nesse artigo permitem apresentar um panorama da constituição étnica do Alto Paraguai no século XVI, além da relação 
entre espanhóis e indígenas, a tentativa de conquista dos últimos e o protagonismo indígena frente as expedições dos invasores espanhóis. A busca pela Sierra de la Prata e das riquezas que acreditavam existir no Pantanal parece dominar o imaginário europeu na região platina de grande parte do século XVI.

Após o início do processo de conquista, as encomiendas e, posteriormente, as reduciones foram duas formas usadas pelos espanhóis para a dominação europeia da região platina, mas isso não aconteceu de maneira monolítica, sem diversas formas de relações e protagonismo por parte dos povos indígenas. No final do século XVI, os espanhóis passam a navegar pelos rios menores e a fundar povoados em outras partes do Alto Paraguai, como o de Santiago de Xerez, inaugurando outro momento do processo de conquista ibérica.

\section{REFERÊNCIAS}

CABEZA DE VACA, Alvar Nuñez. Naufragios y comentarios. Madrid: Calpe, 1922.

CABEZA DE VACA, Alvar Nuñez. Naufragios y comentarios. 1555. Disponível em: http:// www.memoriachilena.cl/602/w3-article-10028.html. Acesso em: 18 ago. 2015.

COMBÈS, Isabelle. Diccionário étnico: Santa Cruz de la Vieja y su entorno em el siglo XVI. Cochabamba, Bolívia: Instituto de Misionología/Editorial Itinerarios, 2010.

EREMITES DE OLIVEIRA, Jorge. A história indígena no Brasil e em Mato Grosso do Sul. Espaço Ameríndio, Porto Alegre, RS, v. 6, n. 2, p. 178-218, jul./dez. 2012.

EREMITES DE OLIVEIRA, Jorge. As origens do povoamento indígena do Pantanal: aportes para uma nova revisão arqueológica. Pós-História, Assis, SP, v. 11, p. 159-84, 2003.

EREMITES DE OLIVEIRA, Jorge; ESSELIN, Paulo Marcos. Uma história (indígena) da ervamate na região platina: da Província do Guairá ao antigo sul de Mato Grosso. Espaço Ameríndio, Porto Alegre, RS, v. 9, n. 3, p. 278-318, jul./dez. 2015.

JULIEN, Catherine. Desde el Oriente. Documentos para la historia del Oriente boliviano y Santa Cruz la Vieja (1542-1597). Santa Cruz de la Sierra, Bolívia: Fondo Editorial Municipal, 2008.

MARKUN, Paulo. Cabeza de Vaca. São Paulo: Companhia das Letras, 2009.

MAURA, Juan Francisco. El Gran Burlador de América: Alvar Núñez Cabeza de Vaca. [S.I.: s.n.], 2011. (Colección: Estudios y Libros de Parnaseo-Lemir). 
MITRE, Bartolomé. Notas bibliográficas y biográficas. In: SCHMÍDEL, Ulrich. Viaje al Río de la Plata, 1534-1544. Buenos Aires: Cabaut y Cia, 1903 [1567]. Disponível em: http:// www.cervantesvirtual.com/obra-visor/viaje-al-rio-de-la-plata-1534-1554/html/ff3a977882b1-11df-acc7-002185ce6064_82.html. Acesso em: 17 ago. 2015.

SCHMIDL, Ulrico. Relatos de la conquista del Río de la Plata y Paraguay (1534-1554). Tradução de K. Wagner. Madrid: Alianza, 1986.

SCHMIDL, Ulrico. Viaje al Río de la Plata, 1534-1544. Buenos Aires: Cabaut y Cia, 1903 [1567]. http://www.cervantesvirtual.com/obra-visor/viaje-al-rio-de-la-plata-1534-1554/ html/ff3a9778-82b1-11df-acc7-002185ce6064_82.html. Acesso em 17 ago. 2015.

\section{Sobre o autor:}

João Filipe Domingues Brasil - Doutorando em História pela Universidade Salgado de Oliveira (UNIVERSO). Mestre em História pela Universidade Federal da Grande Dourados (UFGD). Graduado em História pela Universidade Católica Dom Bosco (UCDB). E-mail: dominguesbrasil@gmail.com

Recebido em 19 de junho de 2018

Aprovado para publicação em 22 de novembro de 2018 
